\title{
Awareness of Cultural Approach in Engineering Teaching by Lecturers: A Literature Review
}

\author{
https://doi.org/10.3991/ijep.v12i1.24961 \\ Nguyen Tien Long ${ }^{1}$, Do Thi Minh Trang ${ }^{1,2(\bowtie)}$, Pham Van Son ${ }^{3}$ \\ ${ }^{1}$ Hanoi University of Science and Technology, Hanoi, Vietnam \\ ${ }^{2}$ Vietnam Maritime University, Haiphong, Vietnam \\ ${ }^{3}$ Educational Equipment Magazine, Hanoi, Vietnam \\ minhtrang.ctt@vimaru.edu.vn
}

\begin{abstract}
This study uncovers key findings in awareness of cultural approach in engineering teaching by lecturers. A testing-based analysis five selection criteria, twenty-six quality articles were evaluated. Thematic analysis methods are used to analyze and identify key findings. The findings indicate that students' regional cultural background and significant differences in their academic perceptions are valued by lecturers. The results of the article emphasize the view that engineering cultural education is expressed through beliefs, values and assumptions, overcoming differences in expertise and institutions. The findings show that culturally limited understanding of engineering education in current educational institutions is a major challenge. Lecturers believe that the university admissions, students' persistence and multicultural competency can be enhanced when lecturers are interested in cultural differences. The support of colleagues and educational institutions will help lecturers implement cultural approach in teaching. Eleven findings from this study should be used to guide lecturer career development initiatives and improve the effectiveness of education by cultural approach teaching method.
\end{abstract}

Keywords - cultural approach teaching methods, engineering teaching, engineering culture, higher education, lecturers' awareness

\section{$1 \quad$ Introduction}

Over the years, the term "culture" has entered into engineering education discourse and it seems to be implied that engineering education has a special culture. The unique and homogeneous nature of this culture has not been extensively studied, but engineering educators have recognized differences in the expertise and engineering institutions. These differences are reflected in attitudes and behaviors of members in the organization. Most engineering curriculum have common features such as the immutability of the curriculum content and using traditional teaching approaches. Besides, engineering educators argue that cultural theories and models are rooted in anthropology and sociology. Compared with social scientists, engineering educators have a limited general understanding of the relationship between cultural concepts 
and observable behaviors. There are many definitions of "culture" in cultural-related literature, but Schein's triple influence model provides a useful starting point. Schein's model clearly delineates three levels of culture: observable expressions of culture (artifacts), behavioral norm values and shared hypothetical beliefs. Schein defines "culture" is: "A pattern of shared basic assumptions that a group learns as it solves its problems of external adaptation and internal integration, that has worked well enough to be considered valid and, therefore, to be taught to new members as the correct way to perceive, think and feel in relation to those problems" [1].

In the trend of global integration, in order to meet the demand for recruitment conditions suitable to the global culture of enterprises, higher education institutions need to renew their curriculum and pedagogical methods towards globalization. One of the most important issues to consider is that the cultural factor of students has a significant effect on the effective teaching methods of lecturer and the organizational culture in higher education. Students from different cultures have different learning styles [2]. Studies of international students' multicultural adaptation, for example, have concluded that students from underdeveloped economic sectors tend to exhibit collectiveism. Members of collective culture often have traditional thoughts, have high obligations and responsibility to the group's duties. And students from the developed economic sector tend to show individualism. Members of individual cultures emphasize selfreliance, privacy, discovery, creativity, and non-compliance [3]. Due to these cultural differences, students from rural and mountainous areas face great challenges in transitioning from the local to university environment in other developed regions. Higher education institutions need to orient teaching methods to approach students' regional cultural differences to create the best learning stepping stones for students in their academic careers.

Cultural concepts in engineering education are included in a variety of studies, each giving a valuable perspective on the cultural context of engineering education. These views include: gender culture $[4,5]$, cultural differences are the cause of the transformation of students' majors [6], the development of engineering cultural identity [7-9], lecturer culture [10], organizational culture [11], national culture [12], assessment culture [13], institutional culture [14], and cultural change [15]. Each of these perspectives provides valuable insight into aspects of engineering education culture. The hypothesis discussed in this paper is that regional cultural differences can have an effect on the overall organizational culture in the engineering education environment. By examining many existing studies, we have provided a relatively complete report of the key findings of the cultural approach to engineering teaching.

\section{Research method}

\subsection{Research questions}

The purpose of the study is to examine existing literature on lecturers' awareness of engineering education culture. From there, analyze the pedagogical values created when teaching cultural approach and the changes to promote the transformation of 
cultural teaching in higher education. The following questions have been used in this study.

1. How is the lecturers' awareness of engineering education culture reflected in the current studies?

2. What pedagogical values are created when teaching cultural approaches in the current studies?

3. What necessary changes promote the transformation of cultural approach teaching in the current studies?

\subsection{Data sources}

The systematic literature review in this study used the guiding procedure suggested by Brocke et al [16]. The ERIC database is primarily used to accurately search English-published resources related to higher education culture, including articles, books, conference papers, and other education-related materials. The Google Scholar database is also used to further search for additional studies. Haddaway, Collins, Coughlin and Kirk [17] suggested that researchers checkup to the first 300 results from Google Scholar to avoid missing out on any literature. The last searches were made on November 30, 2020.

\subsection{Search strategy}

In systematic literature research, a well-defined literature search strategy is critical to enhance the rigor of theoretical data and ensure accurate results $[18,19]$. The code 'AND' was used to combine keyword groups "engineering culture" or "teaching engineering", "learning engineering" with keyword groups "local culture". The scope of the search in databases is limited to peer-reviewed studies and published in an academic journal. All searches are performed based on article summary. The research selected should also address at least one of the research questions mentioned.

\subsection{Study selection}

Figure 1 shows the literature screening process. To select the appropriate studies, the following criteria were used for the review of abstracts and full text of the articles:

- Criteria 1: Studies published in English.

- Criteria 2: Studies published in a peer-reviewed academic journal.

- Criteria 3: Participants included students, lecturers of higher education institutions.

- Criteria 4: Research is an empirical / survey.

- Criteria 5: The research method is clearly described, sufficient evidence, complete results.

After screening, 26 articles were selected for review. 


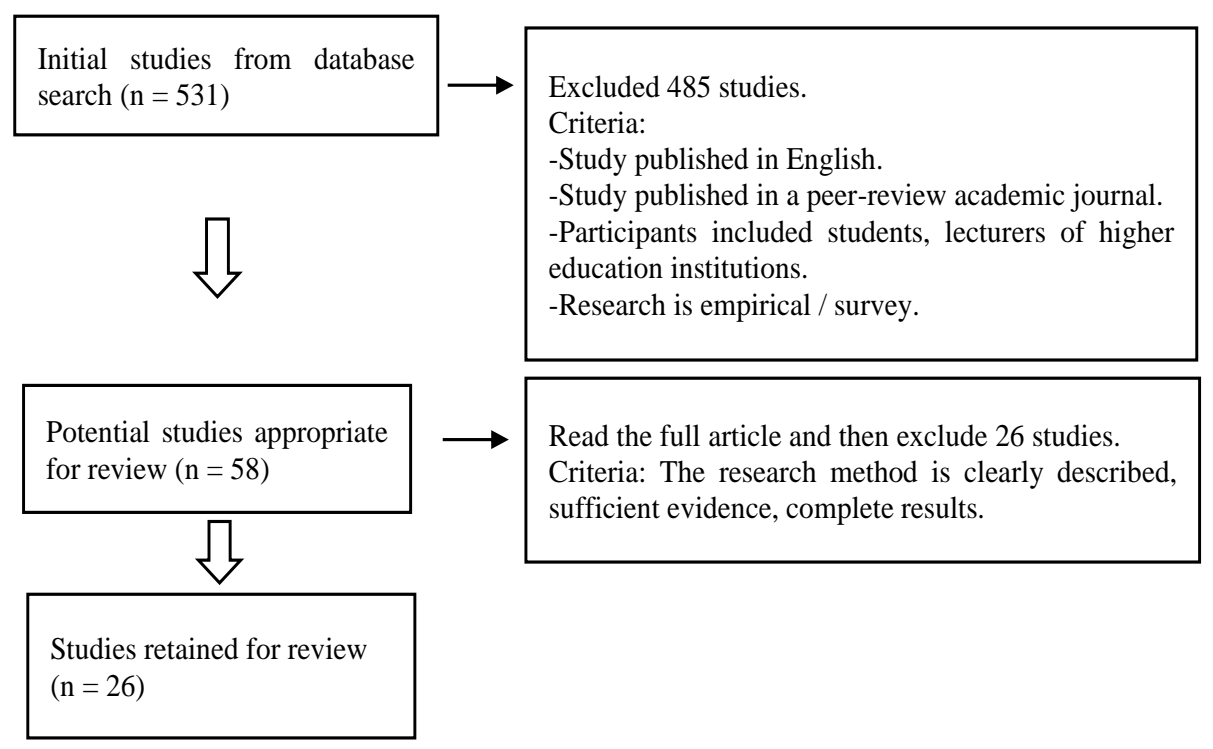

Fig. 1. Diagram of the screening process

\subsection{Data analysis}

The thematic analysis method developed by Braun and Clarke (2006) [20] was used in this study to analyze and identify themes in the data. Braun and Clarke [20] recommend six phases of thematic analysis. The first stage, we read all of the research data to record the original ideas and new findings. In the second stage, we encode feature text and group of data related to each code. In the third stage, we gather the code on potential topics, collecting all relevant data for each potential topic. In the fourth stage, we examine coding the topics and create a "map" of the subject of analysis. In the fifth stage, we refine the specifics of each theme and give each theme a clear name. Finally, in the six stages, we choose vivid examples related to research questions to illustrate and produce an academic analysis report.

We read and discussed all 26 selected articles to establish three encryption protocols including: (1) lecturers' perception, (2) values to education and (3) pedagogical transformation. One author first used these three protocols to code each piece of text extracted from all the articles retained. Five papers were randomly selected for other authors to code the text segments were extracted to test the reliability of the study. This results in a consensus rate of 0.65 (greater than 0.41 ), and the reliability of the study is acceptable [21]. Then we worked together to refine large codes into small ones to detect the main topic. Finally, we retain about 115 text segments extracted from the 26 selected articles. 


\section{$3 \quad$ Results and analysis}

\subsection{How do existing studies show lecturers' awareness of engineering education culture?}

Finding 1: Lecturers believe that there is a significant difference between the learning experience and perceptions of students from different local. We live in a multi-lingual and multicultural society, where cross-cultural crossings and cultural awareness are increasing in most countries. Ramburuth and Tani [22] surveyed approximately 2,200 undergraduates at one of Australia's largest and most diverse universities. Researchers have confirmed that there are significant differences in the learning process of students from different regions including: confidence in communication, enthusiasm in discussions in classroom, interaction with classmates and interaction with lecturers from different language backgrounds. This difference brings new ideas, new ways of thinking, new skills and values in the "fusion of cultures". It also presents cultural challenges such as creating new expectations and requiring more comprehensive approaches to learning and teaching [22]. This also shows that students from different locals need appropriate institutional and learning support to adapt to their new language and learning environment. The reality is that cultures don't build knowledge the same way. There are profound epistemological differences between cultures. Studies of multicultural psychology tell us that one's cognitive framework and cognitive strategy, especially among people from different cultural backgrounds, are extremely confusing and difficult to compare [23]. For example, studying the cognitive and learning processes of engineering students, Holvikivi advocates the notion that standardized and engineering -centered teaching does not adequately meet the needs of multi-student form [24]. The author also points out that certain challenges in the learning process of students are the huge gap between the current and past educational culture, resource constraints in universities. This helps students to be able to adapt to the teaching method available [24].

Finding 2: Lecturers find that students' different learning styles are influenced by different cultures. Loh conducted a survey in a local institution and confirmed the influence of culture on student learning [25]. It cannot be underestimated the role of culture in influencing student learning. Many researchers have concluded that Chinese/Asian students tend to learn passively and rarely participate in classroom discussions. In another finding, Macrae [26] stated that students from "third world" countries were familiar with instructor-led teaching and that even rote learning was allowed. Students become confused when lecturers expect them to take initiative, take responsibility for their own learning, ask questions, and create knowledge independently. In many countries, lecturers are the absolute authority and students are not allowed to challenge them. While the preferred teaching style in Finland is to encourage students to create their own interpretations [25]. In a case study of North American students, Holvikivi found that the outstanding characteristics of students were assertiveness and an active challenge to lecturer [24]. Many documents show that students from different cultural backgrounds have different learning styles. If there is a mismatch between the lecturers's teaching and the student's learning, the teach- 
ing/learning process may be less effective. Studying cultural differences in learning styles in the Ethiopian higher education system [27], King found that the two-way relationship between lecturers and students helps to improve learning efficiency of the students. When teaching diverse students, lecturers need to raise awareness so that they can decode students' knowledge more effectively. In other words, culture can act as a context for building knowledge and positively impacting the teaching process [28]. Julita and Anggoro also identified a learning model based on local culture better than conventional learning model [29].

Finding 3: The lecturers believe that engineering education culture is expressed through beliefs, values and assumptions that transcend differences in expertise and engineering institutions. Godfrey [5] and many others have followed the threedimensional Schein model [30] because it provides a useful starting point, clearly delineating three levels of culture: cultural (artifacts) observations, values and behavioral norms underpin them, and at the deepest level, are the core of shared beliefs and assumptions. Godfrey [5] has proposed a theoretical model of cultural analysis that can be accessed by engineering educators in theory and practice. This model provides a tool to assist researchers, practitioners and policymakers in expressing the nature of culture and the processes of cultural change in engineering education institutions [5]. In another study, Godfrey and Parker [31] gave a conceptual framework on cultural aspects in the context of engineering education such as: Engineering Thinking, Engineering, Become an Engineer, Accept the Difference, Internal Relationship, and External Relationship. The detailed findings from this study, combined with evidence from other studies, support the notion that the six proposed dimensions have the potential to be used as a practical tool for positioning and evaluationing engineering education culture. Stevens also developed an analytical framework called "Becoming an Engineer" that focuses on the changes that occur over time as students enter a university engineering program [8]. Antic and Ceric study organizational culture through the analysis of organizational culture by the Faculty of Civil Engineering of the University of Zagreb [32]. According to a survey presented in this study, lecturers are moderately satisfied with interpersonal relationships, with the selection of new employees, with opportunities for professional advancement and with regulatory requirements. Principle of the Faculty of Engineering. However, the lecturer was not satisfied with the organization's core values system. In addition, a high proportion of lecturer members think that clear rules of behavior should be established for students [32].

Finding 4: Lecturers argue that a culture of engineering education reflects men's attitudes, values and behavioral norms, thereby reinforcing the under-representation of women in Engineering Universities. Godfrey studied the interaction of cultural dimensions with gender through a case at the New Zealand Multidisciplinary Engineering University [33]. Godfrey's model is also based on Schein's theoretical framework that shows masculinity in the core beliefs and assumptions of educational culture, their manifestations in behaviors and practices. Research participants (whether male or female, student or lecturer) perceive women in engineering as different, not only from men but also from other women. The female students seem to build a dual identity. They selectively incorporate in this identity both stereotyped 
masculine and feminine qualities, consistent with their perceptions of simultaneously "being a woman" and "being an engineer". The implication of this study is to provide an accessible theoretical framework for cultural analysis for engineering educators and equity advocates, and to develop cultural change strategies that benefit participation of women. These findings strongly suggest that such strategies must focus on disrupting the duality of language and discourse that implies the formation of the difference, the lack of women in engineering education [33].

Finding 5: Lack of a clear definition of the concept of "culture" in the context of engineering education. There seems to be a major limitation in theory surrounding engineering education culture. Social scientists are accustomed to using the concept of culture. This familiarity helps them easily assert "values, beliefs and assumptions" as a basis for guiding behaviors and practices that are considered cultural norms [34]. Engineers, who often underestimate or ignore findings from qualitative research, seem to have little general understanding of cultural concepts. An example of this lack of clarity is the "culture of engineering education" which implies the heavy workload done by engineering students around the world [5, 35].

Finding 6: Lecturers recognize the importance of culturally responsive teaching in higher education. Restructuring lecturer attitudes and beliefs about cultural, ethnic and racial diversity; culture is centered in the teaching process; and establishing pedagogical connections between culturally responsive instruction with subjects and skills regularly taught in schools are urgent goals of engineering education [36]. The appreciation of cultural factors in the higher education curriculum is a strategic step that has received a positive response from students [37]. In another idea, Kozleski and Waitoller offer a learning model for lecturer to develop practical cultural knowledge in teaching to prepare them for designing a culturally responsive learning environment [38]. Carberry and Baker also highlight the importance of culture and its implications for learning and engineering teaching [39]. In another study, Welzer has incorporated cross-cultural crossings into curriculum to improve the quality of training in educational institutions [40].

\subsection{What pedagogical values are created when teaching cultural approaches in the current studies?}

Finding 7: Lecturers recognize the importance of researching engineering education culture to have practical implications in recruiting and retaining students in engineering schools. For example, Samuelson et al. [41] studied the effect of cultural resources students develop in their communities on engineering education and confirmed that each cultural capital has many different forms each other, contributing to student persistence and success. The more lecturer members understand the concept of cultural resources and the resilience of university students, the more they will be able to exploit the many capacities available to different students [41]. By documenting students' existing cultural backgrounds and documenting cultural change in engineering courses, Melsa et al have further verified the effectiveness of maintaining student resilience in a engineering environment. This integration also 
helps students prepare their full capacity to work in the global industrial market of the twenty-first century [42].

Finding 8: Lecturers suggest that intercultural competencies can be enhanced in engineering education when lecturers are concerned with students' cultural differences. Since engineers often work on projects of different cultural groups, intercultural competency is a necessary part of the learning goal in engineering education. Hoffmann et al have investigated the relationship between CDIO program objectives and intercultural competencies in engineering education [43]. Through discussions based on a social engineering approach to technology and professional engineering practice, the author affirms that intercultural teaching is not only related to cultural differences, but also the ability to communicate between differences to foster mutual learning to solve problems. Since then, the intercultural capabilities of engineering students have been developed in line with the needs of employers. On the other hand, how students conceive of cultural concepts, perceive diversity, and experience interactions between their original cultures on campus are also an opportunity to enhance intercultural competencies. of students [44].

Finding 9: The lecturers claim that teamwork effectiveness will be enhanced by studying the cultures of groups of students from different regions in engineering education. Teamwork skills are increasingly common in engineering organizations. Therefore, engineering students should hone their teamwork skills to meet the expectations of future employers. Tonso studied students' ability to work in groups in an engineering design program and validated the diverse social interactions among engineering students [9]. The effectiveness of the cultural group working model has a great significance in training high-quality human resources [9]. In another idea, Holvikivi argues that teamwork is one of the means to foster student collaboration. Working in a multicultural team can be a rewarding experience for students with the instructor's close guidance and due attention to the composition of the groups [24]. In a study through evaluating integration concepts related to team work and organizational culture, Rodzalan observed that organizational culture can have an impact on team performance of engineering students [45].

\subsection{What necessary changes promote the transformation of cultural approach teaching in the current studies?}

Finding 10: Repositioning and innovating pedagogical methods is an essential requirement to promote the effectiveness of teaching in a multicultural approach. Teaching is culturally responsive, in ideas and actions, and emphasizes locality and specificity of context [36]. It expresses the notion that training activities must be shaped in the socio-cultural context in which they are designed. This idea is sometimes difficult to implement, partly because of educators' desire for "best teaching methods" or the best teaching strategy for all students. In many situations, this poses a lot of challenges for teachers [36]. Rethinking and repositioning of pedagogical methods in the new educational landscape of the 21 st century should call for active participation of students in defining their learning goals. At the same time, 
innovating training strategies in engineering education will bring positive experiences to retain students [39].

Finding 11: Empowering educators, promoting multicultural learning theories are essential requirements to transform teaching into a multicultural approach. For example, a report interviewing 31 engineering graduates from 11 different US universities surveyed students' persistence in engineering through cultural capital types. The findings show a significant effect of an institution's institutional system on students' likelihood of success in the learning processes [41]. These findings can be applied by educators and organizational leaders in practical ways. For example, "family bonding programs" through bringing families to school and providing them with information on how best to support students can enrich cultural capital in schools. In Hoffmann's study, intercultural understanding is important. Cultural aspects of technical education should be reflected in the goals of the CDIO program to develop intercultural competencies in technical education [43]. In general, this poses a challenge for teachers in developing culturally appropriate professional materials and addressing teacher requirements in a way that connects pedagogical knowledge with a multicultural approach.

\section{Conclusion}

Many current studies have demonstrated the positive benefits of engineering teaching with a multicultural approach in improving the effectiveness of technical education [9] [42]. Although this approach has the potential to effectively promote pedagogical (as well as social) practices, their potential is largely unrealized [39]. Therefore, the organizational leaders need to do more specific work to support the lecturer as they strive to integrate a cross-cultural element in the classroom. The 11 findings from this study, found through many existing studies, should be used to guide lecturer's career development initiatives aimed at improving the effectiveness of cross-cultural outreach. Because most cross-cultural outreach pedagogical initiatives are in the form of potential, instruction for new teachers is not available. Therefore, the leaders of higher education institutions should create an environment of open communication and cultural teamwork to promote readiness to share knowledge.

\section{$5 \quad$ Acknowledgment}

Thanks to the supports from Faculty of Civil Engineering, Vietnam Maritime University and School of Engineering Pedagogy in Hanoi University of Science and Technology in Vietnam. This is appreciated acknowledgment for me to complete this study. 


\section{References}

[1] Antić, M., \& Cerić, A. (2008). Organizational culture of faculty of civil engineering, University of Zagreb. Paper presented at the International Conference: Organization, Technology and Management in Construction $(8 ; 2008)$.

[2] Berry, J. W., Berry, J. W., Poortinga, Y. H., Segall, M. H., \& Dasen, P. R. (2002). Crosscultural psychology: Research and applications: Cambridge University Press.

[3] Borrego, M. (2008). Creating a culture of assessment within an engineering academic department. Paper presented at the 2008 38th Annual Frontiers in Education Conference. https://doi.org/10.1109/fie.2008.4720449

[4] Braun, V., \& Clarke, V. (2006). Using thematic analysis in psychology. Qualitative research in psychology, 3(2), 77-101. https://doi.org/10.1191/1478088706ap063oa

[5] Brocke, J. v., Simons, A., Niehaves, B., Niehaves, B., Reimer, K., Plattfaut, R., \& Cleven, A. (2009). Reconstructing the giant: On the importance of rigour in documenting the literature search process.

[6] Carberry, A. R., \& Baker, D. R. (2018). The impact of culture on engineering and engineering education. In Cognition, metacognition, and culture in STEM education (pp. 217 239): Springer.

[7] Colvin, C., Volet, S., \& Fozdar, F. (2014). Local university students and intercultural interactions: Conceptualising culture, seeing diversity and experiencing interactions. Higher education research \& development, 33(3), 440-455. https://doi.org/10.1080/07294360. $\underline{2013.841642}$

[8] Courter, S. S., Millar, S. B., \& Lyons, L. (1998). From the students' point of view: Experiences in a freshman engineering design course. Journal of Engineering Education, 87(3), 283-288. https://doi.org/10.1002/j.2168-9830.1998.tb00355.x

[9] Covington, K., \& Froyd, J. (2004). Challenges of changing faculty attitudes about the underlying nature of gender inequities. age, 9, 1. https://doi.org/10.18260/1-2--13802

[10] Downey, G. L., \& Lucena, J. C. (2005). National identities in multinational worlds: engineers and engineering' cultures. International Journal of Continuing Engineering Education and LifeLong Learning, 15(3-6), 252-260.

[11] Dryburgh, H. (1999). Work hard, play hard: Women and professionalization in engineering - adapting to the culture. Gender \& Society, 13(5), 664-682. https://doi.org/10. $\underline{1177 / 089124399013005006}$

[12] Fromm, E., \& McGourty, J. (2001). Measuring culture change in engineering education. age, 6,1 .

[13] Gay, G. (2013). Teaching to and through cultural diversity. Curriculum inquiry, 43(1), 4870.

[14] Godfrey, E. (2003). A theoretical model of the engineering education culture: A tool for change. age, 8,1 .

[15] Godfrey, E., \& Parker, L. (2010). Mapping the cultural landscape in engineering education. Journal of Engineering Education, 99(1), 5-22.

[16] Godfrey, J. E. (2003). The culture of engineering education and its interaction with gender: A case study of a New Zealand university. Curtin University.

[17] Haddaway, N. R., Collins, A. M., Coughlin, D., \& Kirk, S. (2015). The role of Google Scholar in evidence reviews and its applicability to grey literature searching. PloS one, 10(9), e0138237. https://doi.org/10.1371/journal.pone.0138237

[18] Hoffmann, B., Jørgensen, U., \& Christensen, H. P. (2011). Culture in Engineering Education. CDIO Framing Intercultural Competences. Paper presented at the Proceedings of the 7th International CDIO Conference. 
[19] Holvikivi, J. (2007). Culture and cognition in information technology education. European Journal of Engineering Education, 32(1), 73-82.

[20] Hopia, H., Latvala, E., \& Liimatainen, L. (2016). Reviewing the methodology of an integrative review. Scandinavian Journal of Caring Sciences, 30(4), 662-669. https://doi.org/ $10.1111 / \mathrm{scs} .12327$

[21] Hutchison, C. B. (2006). Cultural constructivism: the confluence of cognition, knowledge creation, multiculturalism, and teaching. Intercultural Education, 17(3), 301-310. https://doi.org/10.1080/14675980600841694

[22] Julita, S., \& Anggoro, A. F. D. (2019). The local culture-based learning model to improve teaching abilities for pre-service teachers. Paper presented at the Journal of Physics: Conference Series. https://doi.org/10.1088/1742-6596/1179/1/012058

[23] Juniati, D., \& Budayasa, I. (2017). Construction of learning strategies to combine culture elements and technology in teaching group theory. World Transactions on Engineering and Technology Education, 15(3), 206-211.

[24] King, A. (2011). Culture, learning and development: A case study on the Ethiopian higher education system. High Educ Res Net J, 4, 5-13.

[25] Kozleski, E. B., \& Waitoller, F. R. (2010). Teacher learning for inclusive education: Understanding teaching as a cultural and political practice. International Journal of Inclusive Education, 14(7), 655-666. https://doi.org/10.1080/13603111003778379

[26] Lewis, S., McLean, C., Copeland, J., \& Lintern, S. (1998). Further explorations of masculinity and the culture of engineering. Australian Journal of Engineering Education, 8(1), 59-78.

[27] Loh, C. Y. R., \& Teo, T. C. (2017). Understanding Asian students learning styles, cultural influence and learning strategies. Journal of Education \& Social Policy, 7(1), 194-210.

[28] Macrae, M. (1997). The induction of international students to academic life in the United Kingdom. Overseas students in higher education: Issues in teaching and learning, 127142. https://doi.org/10.4324/9780203040065-14

[29] McHugh, M. L. (2012). Interrater reliability: the kappa statistic. Biochemia medica, 22(3), 276-282. https://doi.org/10.11613/bm.2012.031

[30] McIlwee, J. S., \& Robinson, J. G. (1992). Women in engineering: Gender, power, and workplace culture: SUNY Press.

[31] McKenna, A., Hutchison, M., \& Trautvetter, L. (2008). The engineer of 2020: Case studies of organizational features of effective engineering education. Paper presented at the Proceedings of research in engineering education symposium.

[32] Melsa, J. L., Rajala, S. A., \& Mohsen, J. (2009). Creating a culture for scholarly and systematic innovation in engineering education. Journal of Engineering Education, 98(3), 209. https://doi.org/10.1002/j.2168-9830.2009.tb01019.x

[33] Nieto, S. (2015). The light in their eyes: Creating multicultural learning communities: Teachers College Press.

[34] Ramburuth, P., \& Tani, M. (2009). The impact of culture on learning: Exploring student perceptions. Multicultural Education \& Technology Journal. https://doi.org/10.1108/ 17504970910984862

[35] Rodzalan, S. A., \& Saat, M. M. (2013). The influence of organizational culture on engineering students' team working skill development. Skudai, Johor: Université des technologies en Malaisie.

[36] Samuelson, C. C., \& Litzler, E. (2016). Community cultural wealth: An assets- based approach to persistence of engineering students of color. Journal of Engineering Education, 105(1), 93-117. https://doi.org/10.1002/jee.20110 
[37] Schein, E. H. (1984). Coming to a new awareness of organizational culture. Sloan management review, 25(2), 3-16.

[38] Schein, E. H. (2010). Organizational culture and leadership (Vol. 2): John Wiley \& Sons.

[39] Seymour, E., \& Hewitt, N. M. (1997). Talking about leaving: Westview Press, Boulder, CO.

[40] Stevens, R., O'connor, K., Garrison, L., Jocuns, A., \& Amos, D. M. (2008). Becoming an engineer: Toward a three-dimensional view of engineering learning. Journal of Engineering Education, 97(3), 355-368. https://doi.org/10.1002/j.2168-9830.2008.tb00984.x

[41] Tonso, K. L. (2006a). Student engineers and engineer identity: Campus engineer identities as figured world. Cultural Studies of Science Education, 1(2), 273-307. https://doi.org/ 10.1007/s11422-005-9009-2

[42] Tonso, K. L. (2006b). Teams that work: Campus culture, engineer identity, and social interactions. Journal of Engineering Education, 95(1), 25-37. https://doi.org/10.1002/j.21689830.2006.tb00875.x

[43] Triandis, H. C. (2005). Issues in individualism and collectivism research. Paper presented at the Cultural and social behavior: The Ontario symposium.

[44] Welzer, T., Družovec, M., Cafnik, P., Venuti, M. Z., \& Jaakkola, H. (2010). Awareness of Culture in e-learning. Paper presented at the 2010 9th International Conference on Information Technology Based Higher Education and Training (ITHET). https://doi.org/10. 1109/ithet.2010.5480083

[45] Whittemore, R., \& Knafl, K. (2005). The integrative review: updated methodology. Journal of advanced nursing, 52(5), 546-553. https://doi.org/10.1111/j.1365-2648.2005. $\underline{03621 . x}$

\section{Authors}

Nguyen Tien Long work at School of Engineering Pedagogy in Hanoi University of Science and Technology in Vietnam.

Do Thi Minh Trang is lecturer at Faculty of Civil Engineering in Vietnam Maritime University and postgraduate at School of Engineering Pedagogy in Hanoi University of Science and Technology in Vietnam.

Pham Van Son work at Educational Equipment Magazine in Vietnam.

Article submitted 2021-06-20. Resubmitted 2021-07-15. Final acceptance 2021-07-15. Final version published as submitted by the authors. 